\title{
Effect of recurrent mutagenesis on some induced genotypes in safflower (Carthamus tinctorious L.)
}

\author{
Sakr H. G. ${ }^{a^{*}}$, Okaz A. M. A. ${ }^{\text {, }}$ Abd el-zaher I. N. ${ }^{a}$, Haridy M. H. ${ }^{a}$ \\ ${ }^{a}$ Department of Agronomy, Faculty of Agriculture, Al-Azhar University (Assiut Branch), Assiut, Egypt \\ ${ }^{b}$ Department of Agronomy, Faculty of Agriculture, Al-Azhar University, Cairo, Egypt
}

\begin{abstract}
Mutation breeding is a tool to induce new genetic variation for improving agronomical important traits. Thus, an investigation was carried out during two successive growing winter seasons 2017/2018 and 2018/2019 on safflower plants, at the Experimental and Research Farm, Faculty of Agriculture, Al-Azhar University, Assiut, Egypt. Three mutagen treatments i.e., dimethyl sulfoxide, electric shock and gamma rays, were used to isolate the desirable mutants in $\mathrm{M}_{4}$ and $\mathrm{M}_{5}$ generations of thirty three safflower genotypes. Three mutagen treatments were used, such as; the chemical mutation mutagen was more effective than the two other mutagens to induce mutant genotypes. On the other hand, some mutant progenies were derived from gamma rays treatment with dose $20 \mathrm{kr}$ which was more effective mutagen for induction of stable promising mutants in safflower, according to final results of $\mathrm{M}_{5}$ generation, particularly high yielding ability trait, softness and earliness as compared to untreated plants. Concerning the important traits, the results showed that the earliest progenies for flowering date were 11 gave 119 days while, 9 gave 120 days with the h1 treatment and rad. in $\mathrm{M}_{5}$ generation. Also, the results showed that two mutated progenies 9 and 12 gave the highest seed yield/plant, 355.64 and $317.67 \mathrm{gm}$ respectively from $\mathrm{h} 3$ treatment, one progeny 13 gave $382.90 \mathrm{gm}$ from t1 treatment. The seed oil content trait, showed that the highest progenies no.11 and 12, gave 44.80 and $44.76 \%$ respectively, on using $\mathrm{h}_{1}$ treatment, while, the mutated no. 13 gave $45.32 \%$ from t1 treatment. Finally, these results supported that the recurrent mutagenic treatments can be used to induce new mutant safflower genotypes which are characterized by spineless, earliness high seed yield and seed oil content. Thus, they can be involved in breeding programs to get new suitable varieties with high seed and oil yield.
\end{abstract}

Keywords: safflower, mutation breeding, recurrent mutagenesis, gamma rays, heritability.

*Corresponding author: Sakr H. G., 


\section{Introduction}

Safflower seeds have been found 4,000 year-old in Egyptian tombs and were used by Chinese approximately 2,200 years ago. Safflower (Carthamus tinctorius L.) is one of the important oil seed crops and has been traditionally grown for its flowers as a source of dye for coloring food and fibers. Subsequently, it is grown for edible oil, animal meal, bird feed, medicinal uses, as a potential candidate crop for production of plant used in pharmaceuticals and biofuel. Oil of safflower is the richest source of linoleic acid, with average linoleic acid content around $78 \%$ of the total seed oil fatty acids (Velasco et al., 2005). Safflower oil is thought to be one of the highest quality vegetable oils, it contains polysaturated fatty acids as oleic and linoleic acids, which are good for cooking and healthy heart, safflower is considered to have a good taste, cook and health (FernandezMartinez et al., 1993; Singh and Nimbkar, 2006). However, the safflower plant is neglected among oil crops i.e, soybean, rapeseed and sunflower, due to the domination of these three oil seed crops, many other crops are either underutilized or neglected (Khan et al., 2009; Murphy, 1999). Also, some limitations are facing this crop as spineness and decreasing both seed yield and oil percentage (Dajue and Mundel, 1996). These limitations make safflower a weak competitor with the other oil crops. The estimated world production is about 0.622 million tons of seed per year from about 0.736 million hectares (FAO, 2009). At recent statistics according to FAO (2014) statistics, safflower production in the world was realized on an area of 1,010,180 ha with a total world production reaching about 867, 659 tons (Yilmaz et al., 2016). Despite its vast potential and growth adaptability to a wide range of agroecological conditions, safflower remained as a neglected crop due to low seed oil content (28-36\%), spines, fiber rich seed meal and vulnerability to a number of diseases and pests. Safflower species are known to possess several desirable genes such as, drought hardiness, shattering tolerance, non-dormancy of seeds, resistance to safflower fly, rust, and powdery mildew (Sujatha, 2007). Mutagenesis technique has been used successfully in several crops to induce genetic variation for improving of both qualitative and quantitative traits. Over the years, the usage of mutations have increased to create novel variability's, mutations are classified into natural and induced ones. In nature, the natural mutation occurs slightly. Recently, mutagenic agents such as physical, chemical, electric shock mutagen, etc., are considered effective and sufficient for induction of genetically and morphological changes in many plant species, especially the self-fertilized plants (Fahmy et al., 1997; Geetha and Vaidyanathan, 1998; Hajduch et al., 1999; Hassan et al., 2001; Kharkwal, 2000; Mihov et al., 2001; Rakesh and Pratibha, 2014; Solanki and Sharma, 1999; Soliman et al., 2003; Wani and Anis, 2001). More than 1800 cultivars obtained either as direct mutants or derived from their crosses have been released worldwide in 50 countries (Ahloowalia and Maluszynski, 2001). In Egypt, safflower area decreased year after 
year at Upper Egypt, because the suffering of genotypes from many problems as lateness (185 days at maturity), full thorns on leaf and heads, low seed yield and low seed oil content. Therefore, the present study aimed to induce recurrent mutations for earliness, spineless and high seed yield with high oil content as a promising mutant that could be used in breeding program to get new varieties.

\section{Materials and methods}

The present investigation was carried out during two successive winter seasons 2017/18 and 2018/19 at the Experimental Farm, Faculty of Agriculture, Al-Azhar University, Assuit, Egypt. The basic materials (thirty mutated progenies and their three parental lines) were extension of the previous study, master thesis Okaz et al. (2016 b). In the beginning of the previous study, during season 2013/14, seeds from three parental lines of safflower plants were subjected to three mutagen agents i.e; gamma radiation (20 $\mathrm{kr}$ ), dimethyl sulfoxide at 1000, 2000 and $3000 \mathrm{ppm}$ and the third mutagen agent was electrical shock treatments to the plantlets (seedlings) in the presence of water solution containing 30000 and 50000 ppm from monosodium phosphate and sodium nitrate $50000 \mathrm{ppm}$. In the $\mathrm{M}_{1}$ generation (season 2013/14), the mutated plants were morphologically different in spineless heads, red and orange petals, flowering date, seed yield/ plant and seed oil content. Selection was made on these mutants who showed high yield/plant and high seed oil content with early flowering. Self-pollinated seeds from those mutants were harvested individually to represent $\mathrm{M}_{2}$ generation seeds. In the $\mathrm{M}_{2}$ generation (season 2014/15), an experiment was carried out to evaluate the mutant progenies. The means, variances between and within the studied genotypes were calculated, in the same time all segregated plants which didn't show the initial changes were excluded. While, the self-pollinated seeds from the plants maintained changes were harvested individually and taken as the $\mathrm{M}_{3}$ generation seeds. In the $\mathrm{M}_{3}$ generation (season 2015/16), seeds of those mutant progenies were planted, the means and the variances between and within of the mutant progenies were calculated as in $\mathrm{M}_{2}$ generation. In the end of the previous study Okaz et al. (2016 b), during season 2015/16, thirty promising mutants with high yielding ability, increase in seed oil content and with early in flowering date as compared to the parental lines, were isolated to produce $\mathrm{M}_{4}$ generation. In the season 2017/18, $\mathrm{M}_{4}$ generation $\left(\mathrm{R}_{1} \mathrm{M}_{1}\right)$, seeds of the thirty promising mutants which were isolated from the $M_{3}$ generation safflower plants were subjected to the same previous mutagenic treatments, during season 2013/14), with the same dose or method to induce the recurrent mutagenesis (RM) and demonstrate its effect on the subsequent mutated generations. Three mutagenic agents i.e. chemical mutagen (dimethyl sulfoxide), 
electrical shock mutagen and physical mutagen (gamma rays) were used. The concentrations of dimethyl sulfoxide were $1000 \mathrm{ppm}$ ( $\mathrm{h}_{1}$ treatment) on six mutated safflower genotypes, $2000 \mathrm{ppm}$. ( $\mathrm{h}_{2}$ treatment) on three mutated safflower genotypes and 3000ppm ( $h_{3}$ treatment) on six mutated safflower genotypes. The electrical shock mutagen treatments, were prepared in the presence of the chemical solutions as follow; monosodium phosphate $30000 \mathrm{ppm}\left(\mathrm{t}_{1}\right.$ treatment) on four mutated safflower genotypes, monosodium phosphate $50000 \mathrm{ppm}$ ( $\mathrm{t}_{2}$ treatment) on four mutated safflower genotypes and sodium nitrate $50000 \mathrm{ppm}$ ( $\mathrm{t}_{3}$ treatment) on three mutated safflower genotypes. Four mutated safflower genotypes were isolated from gamma rays treatment (20 $\mathrm{kr})$. Table (1) showed that the list of the isolated plants from each mutagenic treatment for each mutated progeny of this investigation. An experiment was carried out in the field, which involved thirty three genotypes i.e.; the three parental lines (untreated plants or control) and thirty mutated progenies. The seed of each mutated plant in $\mathrm{M}_{4}$ generation were planted in three ridges plot, each ridge was 3 meter long in hills $0.3 \mathrm{~m}$ apart. Also, the three parental lines were sown, each parental line was represented by three ridges plot, using randomized completely block design with three replicates.

Table (1): Mean and coefficient of variation (c.v) of days to flowering date, seed yield/plant and seed oil content of mutagenized safflower genotypes under different mutagenic treatments for $\mathrm{M}_{4}$ and $\mathrm{M}_{5}$ generations.

\begin{tabular}{|c|c|c|c|c|c|c|c|c|c|c|c|c|}
\hline \multirow{2}{*}{ Character } & \multicolumn{3}{|c|}{ Days to flowering (day) } & \multicolumn{3}{c|}{ Seed yield/ plant (gm) } & \multicolumn{3}{c|}{ Seed oil content (\%) } \\
\cline { 2 - 14 } & \multicolumn{2}{|c|}{ Mean } & \multicolumn{2}{c|}{$\mathrm{C} . \mathrm{V}(\%)$} & \multicolumn{2}{c|}{ Mean } & \multicolumn{2}{c|}{ C.V(\%) } & \multicolumn{3}{c|}{ Mean } & \multicolumn{2}{c|}{ C.V (\%) } \\
\hline $\begin{array}{c}\text { Generation } \\
\text { Treatment }\end{array}$ & $\mathrm{R}_{1} \mathrm{M}_{1}$ & $\mathrm{R}_{1} \mathrm{M}_{2}$ & $\mathrm{R}_{1} \mathrm{M}_{1}$ & $\mathrm{R}_{1} \mathrm{M}_{2}$ & $\mathrm{R}_{1} \mathrm{M}_{1}$ & $\mathrm{R}_{1} \mathrm{M}_{2}$ & $\mathrm{R}_{1} \mathrm{M}_{1}$ & $\mathrm{R}_{1} \mathrm{M}_{2}$ & $\mathrm{R}_{1} \mathrm{M}_{1}$ & $\mathrm{R}_{1} \mathrm{M}_{2}$ & $\mathrm{R}_{1} \mathrm{M}_{1}$ & $\mathrm{R}_{1} \mathrm{M}_{2}$ \\
\hline Control & 129.22 & 130.00 & 1.27 & 0.57 & 94.47 & 92.51 & 3.28 & 1.34 & 38.77 & 38.73 & 2.20 & 1.39 \\
\hline $\mathrm{h} 1$ & 125.29 & 125.61 & 3.27 & 3.45 & 125.45 & 132.35 & 10.52 & 12.65 & 42.40 & 42.97 & 5.90 & 4.60 \\
\hline $\mathrm{h} 2$ & 127.25 & 127.76 & 2.57 & 1.88 & 102.00 & 111.19 & 9.49 & 12.55 & 43.00 & 43.26 & 5.93 & 3.81 \\
\hline $\mathrm{h} 3$ & 124.23 & 124.51 & 3.30 & 3.32 & 138.00 & 139.76 & 10.32 & 11.07 & 43.22 & 43.51 & 5.38 & 3.27 \\
\hline $\mathrm{t} 1$ & 125.47 & 125.88 & 3.01 & 3.52 & 128.22 & 128.96 & 13.23 & 11.95 & 43.71 & 43.75 & 5.38 & 3.29 \\
\hline $\mathrm{t} 2$ & 127.76 & 128.15 & 3.35 & 3.28 & 141.98 & 143.50 & 8.11 & 11.00 & 43.59 & 43.60 & 5.51 & 2.76 \\
\hline t3 & 125.45 & 124.97 & 2.86 & 2.90 & 127.42 & 129.04 & 12.03 & 11.34 & 43.52 & 43.28 & 5.14 & 3.25 \\
\hline $\mathrm{R}$ & 127.68 & 127.83 & 4.22 & 4.14 & 101.92 & 110.82 & 6.78 & 10.49 & 43.12 & 43.16 & 5.34 & 2.96 \\
\hline
\end{tabular}

The agriculture practices of irrigation, fertilization, weeds and pests control were used as normal recommended for safflower production. The data of the present investigation were recorded on ten guarded plants per plot for each of genotypes. At the harvest, selection was made on the best mutants who showed high yield/plant and high seed oil content with early flowering. Self-pollinated seeds from those mutants were harvested individually to represent $\mathrm{M}_{5}$ generation 
seeds. In the season 2018/19, $\mathrm{M}_{5}$ generation $\left(\mathrm{R}_{1} \mathrm{M}_{2}\right)$, the seed of each selected mutated progeny of the previous $\mathrm{M}_{4}$ generation which maintained the changes was taken, sown and it represented $\mathrm{M}_{5}$ generation and considered as a progeny of heritable mutant plant. From the Tables (2-4), it is clear that all mutagenic treatments induced the different types of changes. The total number of selected mutant plants were 24 , in which four mutations due to $h_{1}$ treatment, two mutations due to $h_{2}$ treatment, seven mutations due to $h_{3}$ treatment, three mutations due to $t_{1}$ treatment, three mutations due to $t_{2}$ treatment, three mutations due to $t_{3}$ treatment and two mutations due to rad. treatment. Mutated plants are high in both seed yield and seed oil content per plant. An experiment was carried out in the field, which involved twenty seven genotypes i.e.; the three parental lines (untreated plants or control) and twenty four mutated genotypes. All the agricultural practices in the previous $\mathrm{M}_{4}$ generation were carried out on $\mathrm{M}_{5}$ generation. Measurements and statistical analysis for both seasons $\left(\mathrm{M}_{4}\right.$ and $\mathrm{M}_{5}$ generations) were as done.

Table (2): The morphological description and parent-offspring regression in mutated plants derived from chemical treatments.

\begin{tabular}{|c|c|c|c|c|c|c|c|c|c|c|c|}
\hline \multicolumn{2}{|l|}{ Character } & \multicolumn{3}{|c|}{ Days to flowering date (day) } & \multicolumn{3}{|c|}{ Seed yield/plant (gm) } & \multicolumn{3}{|c|}{ Seed oil content $(\%)$} & \multirow{2}{*}{$\begin{array}{l}\text { Color flower- } \\
\text { Texture plant }\end{array}$} \\
\hline Treatment & Genotype & $\mathrm{M}_{3}$ & $\mathrm{R}_{1} \mathrm{M}_{1}$ & $\mathrm{R}_{1} \mathrm{M}_{2}$ & $\mathrm{M}_{3}$ & $\mathrm{R}_{1} \mathrm{M}_{1}$ & $\mathrm{R}_{1} \mathrm{M}_{2}$ & $\mathrm{M}_{3}$ & $\mathrm{R}_{1} \mathrm{M}_{1}$ & $\mathrm{R}_{1} \mathrm{M}_{2}$ & \\
\hline \multirow{3}{*}{$\mathrm{h}_{1}$} & 1 & 127 & 127 & 128 & 139.51 & 131.56 & 164.33 & 40.46 & 41.20 & 43.67 & sleek - yellow \\
\hline & 12 & 127 & 125 & 124 & 209.33 & 136.38 & 278.68 & 38.38 & 45.50 & 44.76 & sleek - yellow \\
\hline & 27 & 130 & 123 & 126 & 149.35 & 147.64 & 170.31 & 45.67 & 39.70 & 43.47 & sleek - yellow \\
\hline $\mathrm{h}_{2}$ & 4 & 127 & 126 & 126 & 187.87 & 105.58 & 181.74 & 39.57 & 41.80 & 44.55 & thorns - orange \\
\hline \multirow{6}{*}{$\mathrm{h}_{3}$} & 8 & 126 & 127 & 126 & 167.64 & 149.30 & 268.79 & 43.09 & 39.8 & 44.19 & sleek - yellow \\
\hline & 9 & 126 & 127 & 126 & 127.23 & 159.16 & 355.64 & 44.13 & 44.20 & 44.24 & thorns - red \\
\hline & 10 & 129 & 128 & 129 & 120.46 & 145.06 & 172.95 & 43.55 & 39.70 & 44.51 & sleek - yellow \\
\hline & 11 & 125 & 128 & 128 & 103.88 & 157.36 & 175.98 & 40.60 & 41.30 & 44.43 & sleek - yellow \\
\hline & 12 & 128 & 126 & 125 & 93.04 & 145.36 & 317.67 & 40.58 & 42.40 & 44.52 & thorns - yellow \\
\hline & 24 & 128 & 123 & 127 & 120 & 152.70 & 180.65 & 40.11 & 42.80 & 43.63 & thorns - yellow \\
\hline
\end{tabular}

$\mathrm{R}_{1} \mathrm{M}_{1}=\mathrm{M}_{4}$ generation. $\mathrm{R}_{1} \mathrm{M}_{2}=\mathrm{M}_{5}$ generation.

\subsection{Measurements}

Days to flowering date (day), was measured as number of days from sowing to the first flower on the plant, seed yield/plant (gm) and seed oil content (\%), was estimated by Soxhelt apparatus according to AOAC (1980).

\subsection{Statistical analysis}

The mean and coefficient of variation (c.v) of the mutants cached from each mutagenic treatment were calculated and compared with that of the same number of plants representing control treatment was made for RCBD, estimation of mean, the 
coefficient of variation (c.v), were calculated according to Gomez and Gomez (1984), the analysis of regression coefficient for the parents and its offspring which represent heritability in narrow sense was estimated according to Mather (1949).

\section{Results and Discussion}

At the first season of the investigation all mutagenic treatments induced recurrent mutagenized plants for different desired traits such as smooth leaves, red and orange petals, earlier flowering and high yielding ability plants. Tables (2-4) showed that the chosen mutants in $\mathrm{R}_{1} \mathrm{M}_{1}$ $\left(\mathrm{M}_{4}\right.$ generation) after applying the mutagen treatments. It is clear from results, that mutants differed from the original plants of different safflower parental genotypes in three main characters i.e. days to flowering date (D.F), seed yield/plant (S.Y/P) and seed oil content /plant (\%). In addition to thorns and sleek and petal color (Kotcha et al., 2007). Results showed that all mutagens (chemical, electric shock and radiation) have led to induce of mutations in all safflower genotypes. The obtained plants in $\mathrm{M}_{4}$ generation which shown in Tables (2-4) were planted to produce the $\mathrm{M}_{5}$ generation. The means and the variances of the mutagenized plants under different mutagenic treatments were calculated and compared with the same number of untreated plants (control) for the three main traits i.e. number of days from sowing to flowering, seed yield/ plant and oil content percentage /plant (Table 1).

Table (3): The morphological description and parent-offspring regression in mutated plants derived from electric shock treatments.

\begin{tabular}{|c|c|c|c|c|c|c|c|c|c|c|c|}
\hline \multicolumn{2}{|l|}{ Character } & \multicolumn{3}{|c|}{ Days to flowering date (day) } & \multicolumn{3}{|c|}{ Seed yield/plant (gm) } & \multicolumn{3}{|c|}{ Seed oil content $(\%)$} & \multirow{2}{*}{$\begin{array}{l}\text { Color flower- } \\
\text { Texture plan }\end{array}$} \\
\hline \begin{tabular}{|c|} 
Treatment \\
\end{tabular} & Genotype & $\mathrm{M}_{3}$ & $\mathrm{R}_{1} \mathrm{M}_{1}$ & $\mathrm{R}_{1} \mathrm{M}_{2}$ & $\mathrm{M}_{3}$ & $\mathrm{R}_{1} \mathrm{M}_{1}$ & $\mathrm{R}_{1} \mathrm{M}_{2}$ & $\mathrm{M}_{3}$ & $\mathrm{R}_{1} \mathrm{M}_{1}$ & $\mathrm{R}_{1} \mathrm{M}_{2}$ & \\
\hline \multicolumn{2}{|l|}{ Control } & 130 & 129 & 130 & 75.25 & 94.47 & 92.51 & 37.98 & 38.77 & 38.73 & thorns - yellow \\
\hline \multirow{2}{*}{$\mathrm{t} 1$} & 12 & 127 & 127 & 126 & 145.86 & 148.63 & 190.37 & 42.45 & 45.3 & 44.29 & thorns - red \\
\hline & 19 & 125 & 125 & 129 & 128.4 & 154.36 & 173.56 & 39.41 & 39.2 & 44.23 & sleek - red \\
\hline \multirow[b]{2}{*}{$\mathrm{t} 2$} & 5 & 126 & 128 & 129 & 125.29 & 148.08 & 195.44 & 38.68 & 43.00 & 43.13 & sleek - yellow \\
\hline & 6 & 116 & 128 & 127 & 188.44 & 133.09 & 217.18 & 40.07 & 46.50 & 44.53 & thorns - orange \\
\hline \multirow[t]{2}{*}{$\mathrm{t} 3$} & 2 & 129 & 120 & 121 & 202.13 & 144.52 & 313.62 & 39.62 & 43.80 & 43.61 & thorns - yellow \\
\hline & 9 & 126 & 128 & 122 & 94.26 & 124.86 & 175.83 & 42.76 & 39.50 & 44.5 & sleek -orange \\
\hline \multicolumn{3}{|c|}{ Regression coefficient } & -0.28 & -0.07 & & 0.18 & 0.99 & & 0.28 & 0.60 & \\
\hline
\end{tabular}

$\mathrm{R}_{1} \mathrm{M}_{1}=\mathrm{M}_{4}$ generation. $\mathrm{R}_{1} \mathrm{M}_{2}=\mathrm{M}_{5}$ generation.

Table (4): The morphological description and parent-offspring regression in mutated plants derived from gamma rays treatment.

\begin{tabular}{|c|c|c|c|c|c|c|c|c|c|c|c|}
\hline \multicolumn{2}{|l|}{ Character } & \multicolumn{3}{|c|}{ Days to flowering date (day) } & \multicolumn{3}{|c|}{ Seed yield/plant (gm) } & \multicolumn{3}{|c|}{ Seed oil content $(\%)$} & \multirow{2}{*}{$\begin{array}{l}\text { Color flower- } \\
\text { Texture plan }\end{array}$} \\
\hline \begin{tabular}{|l|} 
Treatment \\
\end{tabular} & Genotype & $\mathrm{M}_{3}$ & $\mathrm{R}_{1} \mathrm{M}_{1}$ & $\mathrm{R}_{1} \mathrm{M}_{2}$ & $\mathrm{M}_{3}$ & $\mathrm{R}_{1} \mathrm{M}_{1}$ & $\mathrm{R}_{1} \mathrm{M}_{2}$ & $\mathrm{M}_{3}$ & $\mathrm{R}_{1} \mathrm{M}_{1}$ & $\mathrm{R}_{1} \mathrm{M}_{2}$ & \\
\hline \multicolumn{2}{|l|}{\begin{tabular}{|l|l|} 
Control \\
\end{tabular}} & 130 & 129 & 130 & 75.25 & 94.47 & 92.51 & 37.98 & 38.77 & 38.73 & thorns - yellow \\
\hline $\mathrm{rad}$ & 7 & 126 & 125 & 126 & 166.56 & 112.29 & 174.12 & 42.38 & 39.80 & 43.67 & thorns - yellow \\
\hline \multicolumn{3}{|c|}{ Regression coefficient } & -0.22 & 0.97 & & 0.10 & 0.55 & & -0.01 & 0.94 & \\
\hline
\end{tabular}

$\mathrm{R}_{1} \mathrm{M}_{1}=\mathrm{M}_{4}$ generation. $\mathrm{R}_{1} \mathrm{M}_{2}=\mathrm{M}_{5}$ generation. 
3.1 Effect of chemical mutagen treatments on the studied traits

\subsubsection{Days to flowering (day)}

Results in Tables (1-2) and Figure (1), illustrated that the average number of days to flowering for mutated plants of $h_{1}$ treatment ranged from 119 for mutant no. 11 to 128 days for mutant no. 1 , with an average 125.61 days as against 130 days for the untreated plants, The genotypes 11 and 12 were the earliest in the flowering date, gave 119 and 124 days, respectively. The average of $h_{2}$ treatment was 127.76 days, two genotypes 4 and 6 gave 126 days, and they are the earlier than the untreated plants with 130 days. While, the average number of days to flowering for mutated plants of $h_{3}$ treatment in $R_{1} M_{2}$ $\left(\mathrm{M}_{5}\right.$ generation) ranged from 125 for mutant no. 12 to 129 days for mutant no. 10 , with an average of 124.51 days. The genotype 12 with 125 days and 9 with 126 days, were more responsive to chemical mutagen $\left(\mathrm{h}_{3}\right.$ treatment $)$ as compared to the untreated plants with 130 days. These results are in agreement with those of Dhole et al. (2003), Sheeba et al. (2005), Mensah and Obadoni (2007), Nuraet al. (2013), Gopinath and Pavadai (2015), Ravichandran and Jayakumar (2015), Okaz et al. (2016a) and Ahmad (2019). The coefficient of variation (c.v) is one of variation parameter, its values were categorized as low $(<10 \%)$, moderate (10 to $20 \%)$ and high (>20\%) as indicated by Subramaniam and Menon (1973). The results showed that all treatments i.e. $\mathrm{h}_{1}, \mathrm{~h}_{2}$ and $\mathrm{h}_{3}$ gave low estimates of variation coefficient (c.v), Table (1) indicated that these three treatments induced low amount of genetic variation in the studied genotypes for days to flowering date.

\subsubsection{Seed yield /plant (gm)}

For the chemical mutagen treatments, the mean seed yield/plant of all mutated plants is presented in Tables (1-2) and Figure (2). The results showed that all plants which maintained of the mutation until $\mathrm{R}_{1} \mathrm{M}_{2}\left(\mathrm{M}_{5}\right.$ generation) surpassed the untreated plants in seed yield /plant trait. The mean seed yield / plant of $\mathrm{h}_{1}$ treatment ranged between 164.33 for mutant no.1 to $278.68 \mathrm{gm}$. for mutant no. 12 with an average of $132.35 \mathrm{gm}$. The genotypes 12 and 11 were the highest in seed yield /plant; they gave 278.68 and $255.36 \mathrm{gm}$. respectively, as compared to untreated plants with $92.51 \mathrm{gm}$. For the $\mathrm{h}_{2}$ treatment, the mean seed yield / plant ranged from 162.57 for mutant no.6 to $181.74 \mathrm{gm}$. for mutant no.4, with an average $111.19 \mathrm{gm}$. These genotypes 6 and 4 were the heaviest in seed yield /plant with percentage 96.45 and $75.73 \%$, respectively as compared to the untreated plants with $92.51 \mathrm{gm}$. Meanwhile, the average of seed yield/plant for $h_{3}$ treatment ranged between 172.95 for mutant no.10 to $355.64 \mathrm{gm}$ for mutant no.9 with an average $139.76 \mathrm{gm}$.The genotype 9 with $355.64 \mathrm{gm}$ and 12 with $317.67 \mathrm{gm}$ were out yielded the others and with percentage 284.43 and 243.39 $\%$, respectively as against $92.51 \mathrm{gm}$ in the untreated plants. These results confirm the findings of Ahmed (2012), Nuraet al. (2013), Ravichandran and Jayakumar (2015), Okaz et al. (2016a) and Ahmad (2019). The results of variation 
coefficient showed that all $\mathrm{h} 1, \mathrm{~h} 2$ and $\mathrm{h} 3$ treatments.

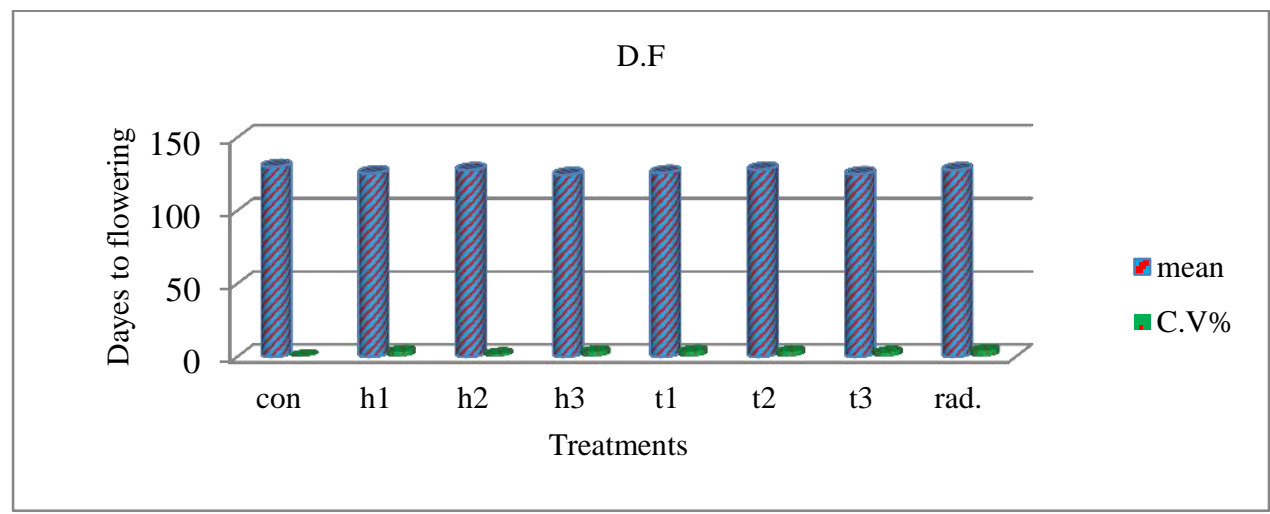

Figure (1): Number of days to flowering of safflower genotypes under different mutagenic treatments in 2018/2019 season.

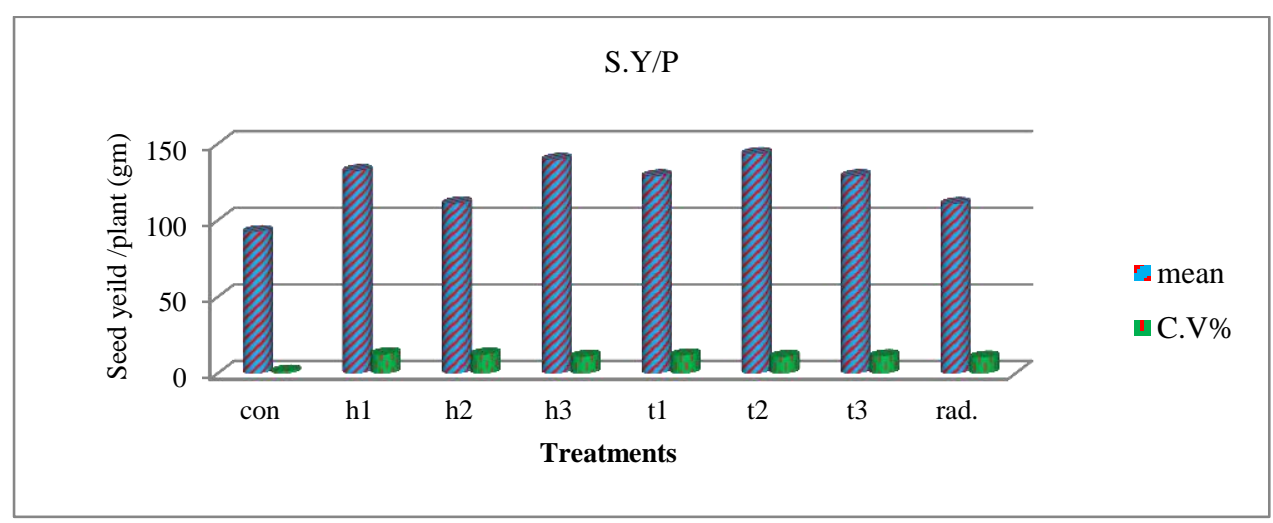

Figure (2): Seed yield/ plant of safflower genotypes under different mutagenic treatments in 2018/2019 season.

Table (1) gave moderate estimates of c.v pointing out that these three treatments induced moderate amount of genetic variation in the studied genotypes for seed yield/plant. This amount can lead to enhance this trait.

\subsubsection{Seed oil content (\%)}

The chemical mutagen treatments, for mean of seed oil content of all mutated plants are presented in Tables (1-2) and Figure (3). The results showed that all plants which maintained of the mutation until $R_{1} M_{2}$ exceeded untreated plants in seed oil content. For the $\mathrm{h}_{1}$ treatment, the average seed oil content ranged from 43.47 for mutant no.27 to $44.8 \%$ for mutant no.11 with an average $42.97 \%$. The genotype 11 with $44.80 \%$ and 12 with $44.76 \%$ were the higher of seed oil content than the other mutants and as compared to the untreated plants with $38.73 \%$, this result meaning that these genotypes exceeded the untreated plants with percentage 15.67 and $15.57 \%$, 
respectively. For $\mathrm{h}_{2}$ treatment, the average of seed oil content ranged between 44.48 for mutant no. 6 to $44.55 \%$ for mutant no.4, with an average $43.26 \%$. These genotypes 6 and 4 surpassed the untreated plants $38.73 \%$, with percentage 44.55 and $44.48 \%$, respectively. Also, for the $\mathrm{h}_{3}$ treatment, the average of seed oil content ranged from 43.63 for mutant no. 24 to $44.52 \%$ for mutant no. 12 with an average $43.51 \%$. The genotypes 12 with 44.52 and 6 with $44.48 \%$ were higher of seed oil content than the other mutated plants and as compared to the untreated with $38.73 \%$. The genotypes 12 and 6 exceeded the untreated plants with $38.73 \%$ with percentage (14.94 and 14.85 $\%)$, respectively. Our results were in agreement with those obtained by Dhole et al. (2003), Sheeba et al. (2005), Mensah and Obadoni (2007), Nuraet al. (2013), Gopinath and Pavadai (2015), Ravichandran and Jayakumar (2015), Okaz et al. (2016 a) and Ahmad (2019).

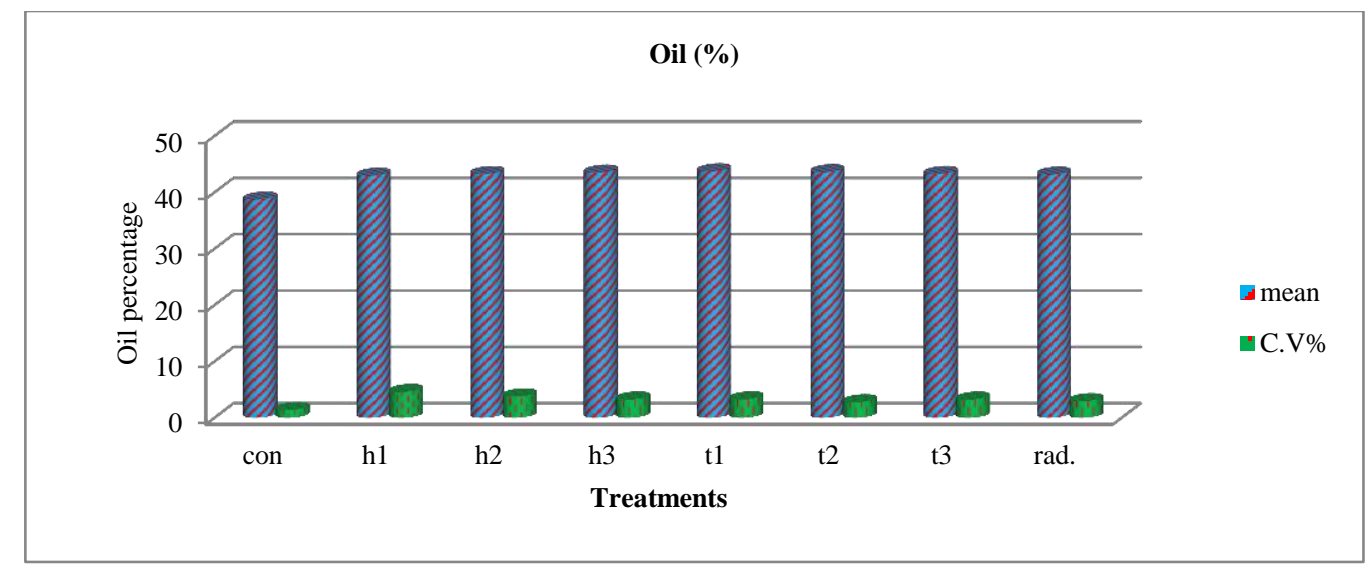

Figure (3): Oil percentage of safflower genotypes under different mutagenic treatments in 2018/2019 season.

The results showed that all treatments of chemical mutagen $\left(\mathrm{h}_{1}, \mathrm{~h}_{2}\right.$ and $\left.\mathrm{h}_{3}\right)$ gave low estimates of variation coefficient (c.v), Table (1) indicated that these three treatments induced low amount of genetic variability in the studied genotypes for seed oil content. The parent-offspring regression coefficients values (Table 2) represent heritability in narrow sense were estimated as follow; -0.62 and -0.26 for days to flowering, -0.07 and 0.45 for seed yield /plant and 0.06 and 0.17 for seed oil content $\%$ for $\mathrm{M}_{4}$ and $\mathrm{M}_{5}$ generation, respectively. The large proportion of the total genetic variation due to the additive genetic effects for days to flowering with -0.62 and seed yield /plant with 0.45 in $\mathrm{M}_{4}$ and $\mathrm{M}_{5}$ generations, respectively, indicating that efficiency of selection for these two traits. These results were in line with those from variation coefficient values.

\subsection{Effect of electric shock mutagen treatments on the studied traits}

\subsubsection{Days to flowering (day)}

The results in Tables (1 and 3) and Figure (1), showed that the average no. of days 
to flowering for mutated plants of $t_{1}$ treatment in $\mathrm{R}_{1} \mathrm{M}_{2} \quad\left(\mathrm{M}_{5}\right.$ generation), ranged from 124 for mutant no.13 to 129 days for mutant No.19, with an average of 125.88 days. The genotypes 13 with 124 and 12 with 126 days were more responsive to electric shock mutagen $\left(\mathrm{t}_{1}\right.$ treatment) as compared to the untreated plants with 130 days. While, the average number of days to flowering date for mutated plants of $t_{2}$ treatment ranged between 125 for mutant No.8 to 129 days for mutant no. 5 with an average 128.15 days. The genotype 8 with 125 days and 6 with 127 days were decreased in days to flowering date as compared to the untreated plants with 130 days. For $t_{3}$ treatment, the mean of days to flowering ranged from 121 for mutant no. 2 to 128 for mutant no.1with an average 124.97 days. The genotype 2 with 121 days and 9 with 122 days were the earlier than the untreated plants with 130 days. These results coincides with Okaz et al. (2016a) when used electric shock on safflower, (Ahmad, 2011) when used electric shock on wheat. The results of variation coefficient showed that the electric shock treatments i.e. $t_{1}, t_{2}$ and $t_{3}$ had low estimates of variation coefficient (c.v), Table 1, indicating that these three treatments induced low amount of genetic variability in the studied genotypes for days to flowering.

\subsubsection{Seed yield/plant (gm)}

For the electric shock mutagen treatments, the mean seed yield/plant of all mutated plants is presented in Tables (1 and 3) and Figure (2). The results showed that all plants which maintained of the mutation until $\mathrm{R}_{1} \mathrm{M}_{2} \quad\left(\mathrm{M}_{5}\right.$ generation) were surpassed untreated plants in seed yield /plant trait. The mean seed yield / plant of $t_{1}$ treatment ranged between 173.56 for mutant no. 19 to 382.9 gm. for mutant no.13 with an average of $128.96 \mathrm{gm}$. The genotype 13 with 382.9 and 12 with $190.37 \mathrm{gm}$. were most responsive to electric shock and gave the highest seed yield /plant with percentage $313.90 \%$ and 105.78 as compared to untreated plants with $92.51 \mathrm{gm}$. Meanwhile, for the $t_{2}$ treatment, the average seed yield/plant ranged from 195.44 for mutant no.5 to $217.18 \mathrm{gm}$. for mutant no. 6 with an average $143.5 \mathrm{gm}$. The genotype 6 with 217.18 and 8 with $199.07 \mathrm{gm}$. were the heaviest with percentage 134.76 and $115.19 \mathrm{gm}$ in seed yield/plant as against $92.51 \mathrm{gm}$ for untreated plants. Also, the mean seed yield /plant for $\mathrm{t}_{3}$ treatment ranged from 157.84 for mutant no.1 to 313.62 for mutant no. 2 with an average $129.04 \mathrm{gm}$. Some genotypes i.e 2 with 313.62 and 9 with 175.83 were the highest yield /plant with percentage 239.01 and $90.1 \%$ as compared to untreated plants with 92.51 gm. This result coincides with Okaz et al. (2016 a) when used electric shock on safflower (Ahmad, 2011) when used electric shock on wheat. The results of variation coefficient (c.v) showed that all $t_{1}, t_{2}$ and $t_{3}$ treatments. Table (1) had moderate estimates of c.v, indicating that these treatments induced moderate amount of genetic variability in the studied genotypes for seed yield plant. This amount can lead to improve this trait.

\subsubsection{Seed oil content (\%)}

The electric shock mutagen treatments, 
for mean of seed oil content of all mutated plants are presented in Tables (1 and 3 ) and Figure (3). The results showed that all plants which maintained of the mutation until $\mathrm{M}_{5}$ generation exceeded untreated plants in seed oil content. For the $t_{1}$ treatment, the average seed oil content ranged from 44.23 for mutant no. 19 to $45.32 \%$ for mutant no. 13 with an average $43.75 \%$.The genotype 13 with $45.32 \%$ and 12 with $44.29 \%$ were most responsive to electric shock with percentage 17.02 and $14.36 \%$, respectively, as compared to the untreated plants with $38.73 \%$.While, for $t_{2}$ treatment, the average of seed oil content ranged between 43.13 for mutant no. 5 to $44.53 \%$ for mutant no. 6 with an average $43.60 \%$. The genotype 6 with 44.53 and 8 with $43.37 \%$ were the highest of seed oil content, with percentage 14.98 and 11.98 $\%$, respectively, as against $38.73 \%$ for the untreated plants. In electric shock mutagen, $t_{3}$ treatment, results showed that mean seed oil content ranged from 43.59 (4-2-1) to $44.5 \%$ (1-1-9) with an average $43.28 \%$. The genotypes 9 with $44.5 \%$ and 2 with $43.61 \%$ were the highest of seed oil content with percentage 14.90 and $12.60 \%$ as compared to $38.73 \%$ for untreated plants. This result coincides with Okaz et al. (2016a) and (Ahmad, 2011) when they used electric shock on safflower and wheat respectively. The results of variation coefficient (c.v) showed that all $\mathrm{t}_{1}, \mathrm{t}_{2}$ and $\mathrm{t}_{3}$ treatments, Table 1(), had low estimates of (c.v), indicating that these three treatments induced low amount of genetic variability in the studied genotypes for seed oil content. The analysis of regression coefficient for the parents and its offspring which represent heritability in narrow sense, Table 3, showed that the estimated values for studied traits, were 0.28 and -0.07 for days to flowering date, 0.18 and 0.99 for seed yield /plant and 0.28 and 0.60 for seed oil content for $\mathrm{M}_{4}$ and $\mathrm{M}_{5}$ generations, respectively. The large proportion of the total genetic variation due to the additive genetic effects for seed yield /plant with 0.99 and seed oil content with 0.60 in $\mathrm{M}_{5}$ generation, indicating that efficiency of selection for these two traits.

\subsection{Effect of physical mutagen treatment (gamma rays) on the studied traits}

The results of the physical mutagen treatment (gamma rays, dose $20 \mathrm{kr}$ ), Tables (1 and 4) and Figure (1), showed that all mutated plants which maintained of the mutations until $\mathrm{R}_{1} \mathrm{M}_{2} \quad\left(\mathrm{M}_{5}\right.$ generation) exceeded untreated plants for all studied traits.

\subsubsection{Days to flowering (day)}

The mean of days to flowering date of (gamma rays, dose $20 \mathrm{kr}$ ), Tables (1 and 4), ranged between 120 for mutant no. 9 to 126 days for mutant no.7 with an average of 127.83 days. The genotype 9 with 120 days and 7 with 126 days were earlier than the untreated plants with 130 days. This result coincides with those of Mia and Shaikh (1997), Veena and Ravikumar (2003), Sheeba et al. (2005), Gopinath and Pavadai (2015) and Okaz et al. (2016a).

\subsubsection{Seed yield /plant (gm)}

Results of mean seed yield/plant, Tables 
(1 and 4), showed that the average ranged from 154.54 for mutant no.9 to 174.12 gm. for mutant no.7 with an average $110.82 \mathrm{gm}$. The genotype 7 and 9 were the higher in seed yield /plant with percentage 88.22 and $67.10 \%$ as compared to the untreated plants with $92.51 \mathrm{gm}$. This result coincides with those of Mia and Shaikh (1997), Veena and Ravikumar (2003), Sheeba et al. (2005), Cvejic et al. (2011), Gopinath and Pavadai (2015) and Okaz et al. (2016a).

\subsubsection{Seed oil content (\%)}

For seed oil content, results in Tables (1 and 4), showed that the genotypes 7 and 9 gave the same performance with $43.67 \%$, and were higher in seed oil content, with percentage 12.75 as against $38.73 \%$ for the untreated plants. This result coincides with those of Mia and Shaikh (1997), Veena and Ravikumar (2003), Sheeba et al. (2005), Cvejic et al. (2011), Gopinath and Pavadai (2015) and Okaz et al.(2016 a), but opposite with that obtained by Siddiqui et al (2009), who reported that no treatment could produce oil $(\%)$ higher than control. The variation coefficient (c.v) estimates, Table (1), showed low values of days to flowering date and seed oil content. Meanwhile, the c.v value was moderate for seed yield/plant. The parentoffspring regression coefficients values (Table 4), representing heritability in narrow sense, were estimated as follow; 0.22 and 0.97 for days to flowering date, 0.10 and 0.55 for seed yield/plant and 0.01 and 0.94 for seed oil content in $\mathrm{M}_{4}$ and $\mathrm{M}_{5}$ generations, respectively. The large proportion of the total genetic variation due to the additive genetic effects for days to flowering with 0.97, seed yield / plant with 0.55 and seed oil content with 0.94 in $\mathrm{M}_{5}$ generation, indicating that efficiency of selection for these studied traits.

\section{Conclusions}

Using the different mutagen treatments were effective tool to obtain new safflower genotypes with spineless, earliness and high seed yield. We can use these new genotypes in breeding programs to obtain new suitable varieties for cultivation at reclaimed desert lands as a new oil crop in Egyptian agriculture. In general, the chemical mutagen $\left(\mathrm{h}_{3}\right.$ treatment) was more effective than the two other treatments to induce mutagenized plants for days to flowering date with an average (124.51 days), seed yield /plant with an average (139.76 gm.) and seed oil content with an average $(43.51 \%)$ as compared (130 days, 92.51 gm. and $38.73 \%$ ) for untreated plants in the three studied traits, respectively. For electric shock mutagen ( $t_{2}$ treatment) was more effective than the two other treatments to induce mutations and gave mutant plants for seed yield/ plant with an average (143.50 gm.). While, $\mathrm{t}_{1}$ treatment was efficient to induce mutations and gave mutant plants with high oil percentage $(45.32 \%)$.

\section{References}

Ahloowalia, B. S. and Maluszynski, M. (2001), "Induced mutations - A new paradigm in plant", Euphytica, Vol. 118 No. 2, pp. 167-173.

Ahmad, B. H. (2019), "Induced mutations in some wheat (Triticum 
aestivum L.) genotypes", Assiut Journal of Agriculture, Vol. 50, pp. 27-38.

Ahmad, M. S. (2011), "A new technique for induction of mutations in plant (induction of mutation in bread wheat) Egypt", Journal.Plant Breed, Vol. 15 No. 2, pp. 193-205.

Ahmed, M. E. (2012), 'Mutagenic and Biotechnological studies on safflower (Carthamus tinctorius L.)", M.Sc Thesis, Genetic Department, Faculty of Agriculture, Zagazig University, Egypt.

AOAC (1980), Official Method of Analysis of the Association of Official Agriculture Chemists, $13^{\text {th }}$ Ed., AOAC, Washington, DC., USA.

Begum, T. and Dasgupta, T. (2014), "Induced genetic variability, heritability and genetic advance in sesame (Sesamum indicum L.)", Sabrao Journal of Breeding and Genetics, Vol. 46 No. 1, pp. 21-33.

Cvejic, S., Afza, R., Jocic, S., Prodanovic, S., Miklic, V., Skoric, D. and Dragin, S. (2011), "Radiosensitivity of sunflower inbred lines to mutagenesis", Helia, Vol. 34 No. 54, pp. 99-106 .

Dajue L. and Mündel, H. (1996), "Safflower (Carthamus tinctorious L.)", IPGRI, Rome, Italy and IPK,Gatersleben, Germany.

Dhole, V. J., Maheshwari, J. J. and Patil,
S. (2003), "Studies on mutations induced by EMS in soybean (Glycine max L.)", Agricultural Science Digest, Vol. 23 No. 3, pp. 226-228.

Fagwalawa, (2013), "Morphological characterization of colchicineinduced mutants in sesame (Sesamum indicum L.)", Journal of Biological Sciences, Vol. 13 No. 4, pp. 277-282.

Fahmy, E. M. Rashed, M. A. and Hammad, A. H. A. (1997), "Effect of gamma rays on yield and its components for some soybean cultivars, Glycine max L.", Arab Universities Journal of Agricultural Sciences, Vol. 5, pp. 57-67.

FAO (2009). FAOSTAT Statistical Database, Food and Agriculture Organization of the United Nations (FAO), http:// apps.fao.org.

FAO (2014), FAOSTAT Statistical Database, Food and Agriculture Organization of the United Nations (FAO), http:// apps.fao.org.

Fernandez-Martinez, J., Rio, M. D. and Haro, A. D. (1993), "Survey of safflower (Carthamus tinctorious L.) germplasm for varieties in fatty acid composition and other seed characters", Netherlands Journal of Plant Breeding, Vol. 69, pp. 115122 .

Geetha, K. and Vaidyanathan, P. (1998), "Studies on induction of mutations in soybean (Glycine max L. Merill) 
through physical and chemical mutagens", Agricultural Sciences Digest Karnal, Vol. 18, PP. 27-30.

Gomez, K. A. and Gomez, A. A. (1984), Statistical procedures for agricultural research, John Willy and Sons Inc., New York, USA.

Gopinath, P. and Pavadai, P. (2015), "Morphology and yield parameters and biochemical analysis of soybean (Glycine $\max$ L. Mrr.) using gamma rays, EMS and DES treatments", International Letters of Natural Sciences, Vol. 35, pp. 50-58.

Hajduch, M., Debre, F., Bohmova, B. and Pretova, B. (1999), "Effect of different mutagenic treatments on morphological traits of $\mathrm{M}_{2}$ generation of soybean", Soybean Genetics Newsletter, Vol. 26, http://www.soygenetics.org/articles/ sgn1999-005.html.

Hassan, S., Javed, M. A., Khattak, S. U. K. and Iqpal, M. M. (2001), "A high yielding better quality chickpea mutant variety (NIFA-95)", Mutation Breeding Newsletter, Vol. 45, pp. 6-7.

Kotcha, A., Wongya, W., Wongpiyasatid, A. and Pongtongkam, P. (2007), "Gamma radiation induced genetic variability in population of safflower", Kasetsart University Annual Conference, Bangkok, Thailand, Vol. 12, pp. 257-262.

Mather, K.(1949), Biochemical Genetic,
Dover Publications Inc, London, United Kingdom.

Mensah, J. K. and Obadoni, B. (2007), "Effects of sodium azide on yield parameters of groundnut (Arachis hypogaea L.) ", African Journal of Biotechnology, Vol. 6, pp. 668-671.

Mia, M. F. U. and Shaikh, M. A. Q. (1997), "Induction of large seeded mutants in groundnut (Arachis hypogaea L.) and their yield performance", Sabrao Journal, Vol. 29, pp. 103-104.

Mihov, M., Mehandjiev, A. and Stoyanova, M. (2001), "Mutagenesis as a breeding method in lentil", Mutation Breeding Newsletter, Vol. 45, pp. 32-34.

Nura, S., Adamu, A. K., Mu'Azu, S., Dangora, D. B. and Fagwalawa, L. D, (2013), "Morphological characterization of colchicineinduced mutants in sesame (Sesamum indicum L.)", Journal of Biological Sciences, Vol. 13 No. 4, pp. 277-282.

Okaz, A. M. A., Ahmad M. S. H. and Sakr, H. G. H. (2016 a), "Induced mutation in some safflower genotypes", Assiut Journal of Agriculture of Science, Vol. 47 No. 2, pp. 377-390.

Okaz, A. M. A., Ahmad M. S. H. and Sakr, H. G. H. (2016b) "Effect of some mutagenic agents in improvement of some characters in safflower (Carthamus tinctorius 
L.)", M.Sc. Thesis, Agronomy Department, Faculty of Agriculture, Al-Azhar University, Cairo, Egypt.

Rakesh, C. V. and Pratibha, S. (2014), "Radiation - induced reciprocal translocations in safflower (Carthamus tinctorious L.) ", Cytologia, Vol. 79 No. 4, pp. 54145.

Ravichandran, V. and Jayakumar, S. (2015), "Effect of mutagens on quantitative characters in $\mathrm{M}_{2}$ and $\mathrm{M}_{3}$ generation of sesame (Sesamum indicum L.)", International Letters of Natural Sciences, Vol. 42, pp. 7682.

Siddiqui, M. A., Khan, I. A. and Hatri, A. (2009), "Induced quantitative variability by gamma rays and ethyl methane sulphonate alone and in combination in rapeseed (Brassica napus L.)", Pakistan Journal Botany , Vol. 41, pp. 1189-1195.

Singh, V. and Nimbkar, N. (2006), "Safflower (Carthamus tinctorius L.)", Genetic resources, chromosome engineering and crop improvement, (Singh, R. J, ED.), Boca Raton, Florida, USA, pp. 16794.

Solanki, I. S. and Sharma, B. (1999), "Induction and exploitation of polygenic variability in lentil", Journal of Genetics and Breeding, Vol. 53, pp. 79-86.

Soliman, S. S. A., Eisa, M. S., Ismail, T. A., Naguib, N. A. and Azza, F. E. Wani, A. A. and Anis, M. (2001),
(2003), "Induction of salt tolerance mutants in Faba bean (Vicia faba L.) 1- Promising line mutants under saline and normal soil condition", Zagazig Journal of Agriculture Research, Vol. 30, pp. 213-229.

Subramaniam, S. and Menon, M. (1973), "Inheritance of short stature in rice", Madras Agriculture Journal, Vol. 60, pp. 1129-1133.

Sujatha, M. (2007), "Advances in safflower biotechnology", Functional Plant Science and Biotechnology, Texeira Da Silva (Ed.), Global Science Books, Vol. 1, pp. 160-170.

Veena, K. R. and Ravikumar, R. L. (2003), "Mutagenic effect on homozygous parental lines and heterozygous hybrids in altering character association in safflower", Karnataka-journal of Agricultural sciences, Vol. 16, pp. 390-396.

Velasco, L., Perez-Vich, B. and Fernandez-Martinez，J. M. (2005), "Identification and genetic characterization of a safflower mutant with a modified tocopherol profile", Plant Breeding, Vol. 124, pp. 459-463.

Verma, R. C. and Shrivastava, P. (2014), "Radiation induced reciprocal translocations in safflower ( Carthamus tinctorious L. )", The Japan Mendel Society, Cytologia, Vol. 79, No. 4, pp. 541-545. 
"Gamma rays induced bold seeded high yielding mutant in chickpea", Mutation Breeding Newsletter, Vol. 45, pp. 20-21.

Yilmaz, H., Comak, M. B. and Turgut, F. (2016), "Analysis of factors related to farmer's benefiting from safflower (Carthamus tinctorius L.) production support", Journal. Animal Plant Science, Vol. 26, pp. 1411-1417. 